\title{
STUDY OF NANOSTRUCTURED PLASMA-POLYMER THIN FILMS GROWTH UNDER DUSTY PLASMA CONDITIONS
}

\author{
${ }^{1}$ Vojtěch HOMOLA, ${ }^{1}$ Roman PŘIBYL, ${ }^{1}$ Štěpánka KELAROVÁ, ${ }^{1}$ Richard VÁCLAVÍK, ${ }^{1}$ Petr TOMŠEJ, \\ ${ }^{1}$ Monika STUPAVSKÁ, 'Lukáš ZÁBRANSKÝ, ${ }^{2}$ Anna CAMPBELL CHARVATOVA, \\ ${ }^{2}$ Petr KLAPETEK, ${ }^{1}$ Vilma BURŠÍKOVÁ
}

\author{
${ }^{1}$ Faculty of Science, Masaryk University, Brno, Czech Republic, EU, vilmab@physics.muni.cz \\ ${ }^{2}$ Czech Metrologic Institute, Brno, Czech Republic, EU
}

https://doi.org/10.37904/nanocon.2019.8699

\begin{abstract}
In the present work plasma-polymer nanocomposite thin films were prepared under dusty plasma conditions in capacitively coupled RF discharges. The main focus was on the study of the formation of the organosilicon plasma polymers and their growth. The plasma polymers were grown heterogeneously in form of polymeric particles arising from the discharge volume which incorporated into the amorphous organosilicon polymeric film growing on the silicon and glass substrates. The created nanocomposite structure had very beneficial influence on the film properties. The films showed very interesting mechanical and surface properties. Variation in deposition conditions enabled us to vary the surface free energy of the films. The mechanical properties of the films were studied using nanoindentation technique and the surface structure was studied using atomic force microscopy. The atomic composition and chemical structure of the films were studied studied using XPS and FTIR techniques. The surface free energy of the films was studied using contact angle measuring techniques.
\end{abstract}

Keywords: PECVD, hexamethyldisiloxane, oxygen, mechanical properties, AFM, surface free energy

\section{INTRODUCTION}

Silicon containing plasma polymer coatings are deposited by means of plasma enhanced chemical vapor deposition (PECVD) technologies for many applications ranging from microelectronic industry to aerospace industry and biomedical applications [1-13]. The silicon containing precursors in the mixture with oxygen are often used for preparation of glass-like stochiometric amorphous $\mathrm{SiO}_{2}$ or substoichiometric $\mathrm{SiO}_{x}$ thin films. The coatings prepared from organosilicon or organosilazane compounds may also contain a considerable amount of carbon and hydrogen $\left(\mathrm{SiO}_{x} \mathrm{C}_{y} \mathrm{H}_{z}\right)$. The chemical structure of the films strongly depends on the precursor to oxygen flow-rate, the applied power, the deposition pressure and the bias voltage on the substrate holder. Recently, liquid organosilicon compounds (tetraethoxysilane (TEOS), tetramethoxysilane (TMOS), hexamethyldisilazane (HMDSZ), and hexamethyldisiloxane (HMDSO)) are used as $\mathrm{SiO}_{x}$ or $\mathrm{SiO}_{x} \mathrm{C}_{y} \mathrm{H}_{z}$ precursors instead of the gaseous but hazardous and pyrophoric silane $\left(\mathrm{SiH}_{4}\right)$.

The fundamental mechanisms of the deposition from organosilicon/oxygen mixtures were explored intensively by several research groups, especially for hexamethyldisiloxane (HMDSO, $\mathrm{C}_{6} \mathrm{H}_{18} \mathrm{Si}_{2} \mathrm{O}$ ) plasmas [1-3]. It was found that the HMDSO molecule dissociation is mainly produced by electron impact [1-3]. In the HMDSO molecule $\mathrm{Si}-\mathrm{C}$ and $\mathrm{C}-\mathrm{H}$ bonds are broken preferably, since the bond energies of $\mathrm{Si}-\mathrm{C}(4.5 \mathrm{eV})$ and $\mathrm{C}-\mathrm{H}$ (3.6 $\mathrm{eV})$ are lower than the bond energy of $\mathrm{Si}-\mathrm{O}(8.3 \mathrm{eV})$ [1-3]. Depending on the HMDSO content in the deposition gas mixture it is possible to deposit hard $\mathrm{SiO}_{2}$-like coatings with negligible carbon content (in case if the $\mathrm{HMDSO} / \mathrm{O}_{2}<0.1$ ) as well as soft and elastic polymer-like $\mathrm{SiO}_{x} \mathrm{C}_{y} \mathrm{H}_{z}$ coatings. If the flow rate ratio $\mathrm{HMDSO} / \mathrm{O} 2$ is $<0.1$, the heterogeneous oxidation reactions are dominating, what leads to significant reduction of the carbon content in the film. Depending on the kinetic energy of the ions impinging the surface of the growing film, film densification, surface smoothing and etching the smaller species may occur. In case of the high 
HMDSO to oxygen mixtures carbonated radicals and the abstracted methyl radicals are either directly deposited or undergo homogeneous oxidation reactions and reactions with other hydrocarbon species. The fragments may then be adsorbed on the surface and the carbonated species may be oxidized by atomic oxygen. There is a third pathway of dissociative ionization process, when the HMDSO molecule is losing one of the methyl groups due to electron impact and a $\left(\mathrm{CH}_{3}\right)_{3} \mathrm{SiOSi}\left(\mathrm{CH}_{3}\right)_{2}$ cation is created. The cation produced by the electron impact is a reactive electrophil compared to the oxygen in HMDSO molecule. This reaction may start the oligo-polymerisation process in plasma and leads to the formation of so called "dusty plasma" [4-9].

The dusty plasma is a very attractive tool for deposition of nanocomposite thin films, which could be successfully applied in many industrial and technological applications. This method may also be used to form films whose structure is granular and porous. Dusty plasmas were reported for a wide range of applications. For example, to produce low-k dielectric layers for microelectronics [5], formation of barrier layers [6,47] or biomedical applications [7]. Dusty plasma can also be used as a diagnostic tool for investigating phenomena in discharges [8].

\section{EXPERIMENTAL}

The parallel-plate PECVD reactor was used to prepare nanocomposite $\mathrm{SiO}_{x} \mathrm{C}_{y} \mathrm{H}_{z}$ films. The reaction chamber was made of a glass cylinder closed by two stainless steel flanges. The parallel electrodes were made of graphite and the bottom electrode was capacitively coupled to the RF generator working at frequency of 13.56 $\mathrm{MHz}$. The studied films were deposited low pressure RF glow discharge from a mixture of $\mathrm{HMDSO}\left(\mathrm{C}_{6} \mathrm{H}_{18} \mathrm{Si}_{2} \mathrm{O}\right)$ and oxygen. The ratio of HMDSO flow rate $Q_{H M D S O}$ and the total flow rate $\mathrm{q}\left(\mathrm{q}=Q_{H M D S O} /\left(Q_{H M D S O}+Q_{O 2}\right)\right.$ ) ranged from 0 to 0.95 . The HMDSO flow rate $Q_{H M D S O}$ varied from 1 to $10 \mathrm{sccm}$ and the oxygen flow rate $Q_{02}$ was varied from 2 to $10 \mathrm{sccm}$. The substrates were silicon wafers and glass plates. The applied power $P$ varied from 25 to $75 \mathrm{~W}$ and the $\mathrm{DC}$ negative self-bias voltage $U_{b}$ ranged from -10 to $-400 \mathrm{~V}$.

The instrumented indentation technique was used to study the mechanical properties of the films. The samples were measured by means of Fischerscope H100XYp microindentor and by Hysitron TI 950 (Bruker) nanoindentor equipped with a sharp Berkovich diamond indenter. The indenter diameter was less than $50 \mathrm{~nm}$. The morphology of the film surface and the indentation prints were studied using atomic force microscope (AFM) Ntegra Prima NT-MDT. The Gwyddion software was used to evaluate the AFM images.

The contact angle measurements and the surface free energy (SFE) evaluations were done using the See System (Advex Instruments) equipment and software, respectively. The Lifshitz-Van der Waals/acid-base approach [13] was used to calculate the electron-acceptor and electron-donor parameters of the surface free energy. The total surface free energy is a sum of its disperse $L W$ and acid/base $A B$ components:

$\gamma=\gamma^{L W}+\gamma^{A B}, \quad \gamma^{A B}=2 \sqrt{\gamma^{+} \gamma^{-}}$

where

$\gamma$ - the total surface free energy $\left(\mathrm{mJ} \cdot \mathrm{m}^{-2}\right)$

$\gamma^{W}$ - dispersive Lifshitz-Van der Walls component of SFE $\left(\mathrm{mJ} \cdot \mathrm{m}^{-2}\right)$

$\gamma^{A B}$ - acid-base component of SFE $\left(\mathrm{mJ} \cdot \mathrm{m}^{-2}\right)$

$\gamma^{+}$- acid component $\left(\mathrm{mJ} \cdot \mathrm{m}^{-2}\right)$

$\gamma^{+}$- base component $\left(\mathrm{mJ} \cdot \mathrm{m}^{-2}\right)$

The surface energy can be calculated according to Young-Dupré equation expressed by the following equation: 


$$
\left(1+\cos \theta_{i}\right) \gamma_{i}=2\left(\sqrt{\gamma_{i}^{L W} \gamma_{j}^{L W}}+\sqrt{\gamma_{i}^{+} \gamma_{j}^{-}}+\sqrt{\gamma_{i}^{-} \gamma_{j}^{+}}\right)
$$

where:

$\Theta$ - the contact angle $\left(^{\circ}\right)$ i refers to testing liquid and $\mathrm{j}$ refers to the measured thin film.

Six testing liquids and the least square method was used to determine the coefficients in equation (2).

\section{RESULTS AND DISCUSSION}

A large number of depositions were carried out in a wide range of deposition conditions as a continuation of our previous work presented in [14]. Thin films with a wide range of surface free energy were produced. Moreover, the mechanical properties of prepared films were in the range from hard inorganic $\mathrm{SiO}_{2}$-like properties to soft polymer-like $\mathrm{SiO}_{x} \mathrm{C}_{y} \mathrm{H}_{z}$ films properties.
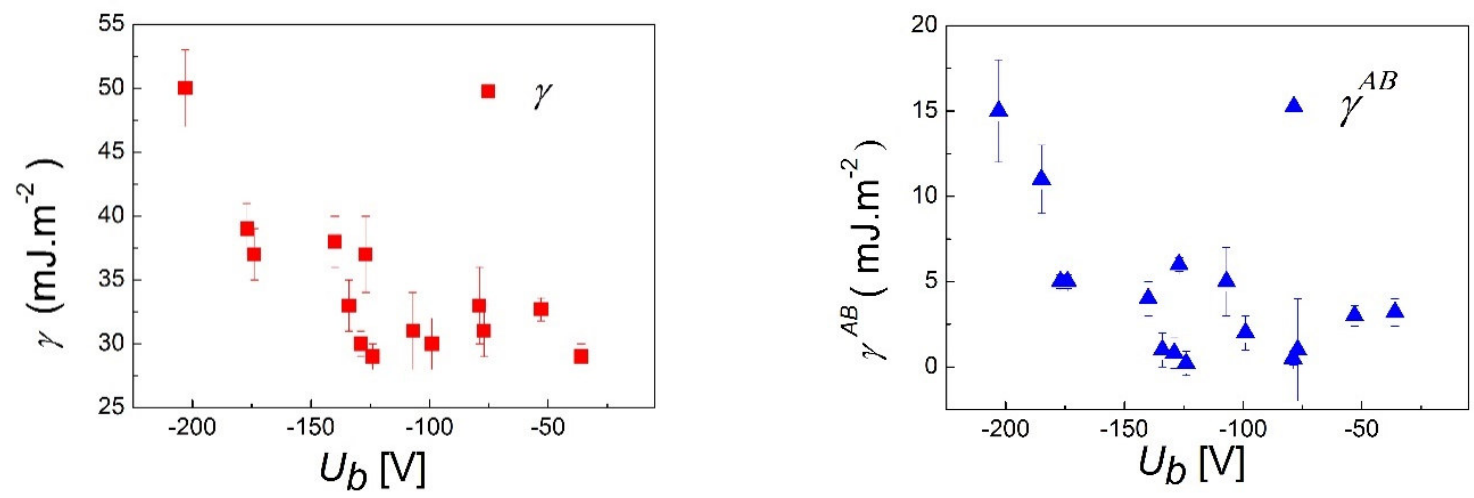

Figure 1 Dependence of the total surface free energy (on the left) and its $A B$ part (on the right) on the self bias voltage $U_{b}$ on the substrate holder electrode.
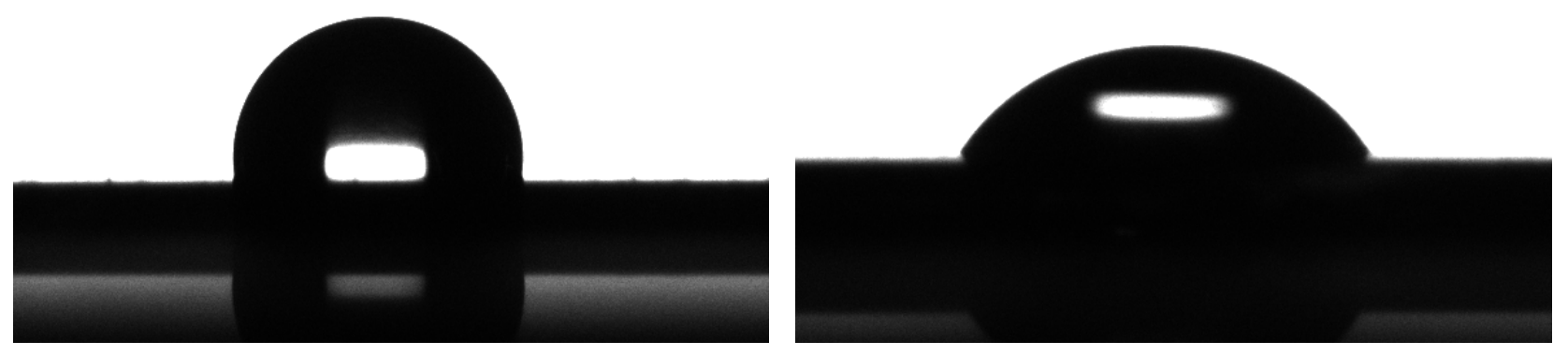

Figure 2 Optical images of the water drops on the hydrophobic coating (on the left) with water contact angle of $(93 \pm 1)^{\circ}$ prepared at low absolute value of $U_{b}$ and on the hydrophilic coating (on the right) with water contact angle of $(60 \pm 1)^{\circ}$ prepared at at low absolute value of $U_{b}$.

In Figure 1 on the left there is a graph illustrating the dependence of the total surface free energy (on the left) and its acid-base part on the DC self-bias voltage. It can be seen that at high absolute value of $U_{b}$ the films exhibited glass-like hydrophilic properties (there is an example of the water contact angle in Figure 2 on the left) in case of low absolute values of $U_{b}$ the films showed hydrophobic behavior (in Figure 2 on the right). Samples prepared at relatively low absolute value of self bias voltage $<120 \mathrm{~V}$ exhibited large elastic recovery and also significant anelastic recovery (similar to selfhealing effect). In Figure 3, there are two examples of the nanoindentation test on organosilicon plasma polymer coating deposited on two different substrates, polycarbonate and single crystal silicon. The HMDSO to oxygen flow rate ratio was 0.18 and the bias voltage was $-110 \mathrm{~V}$. 

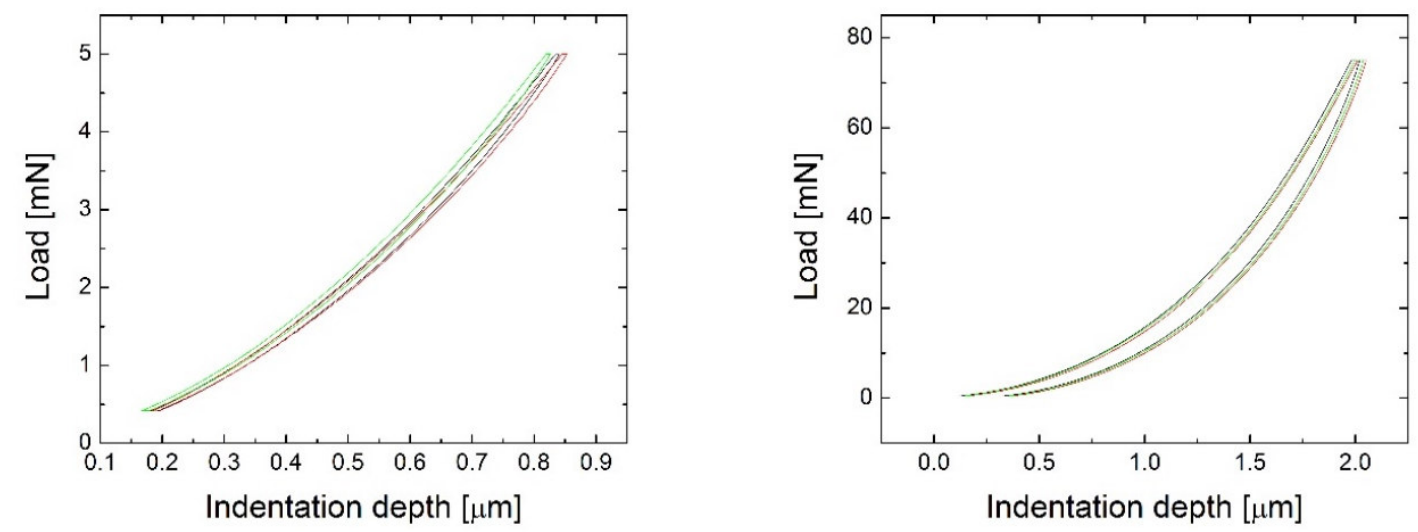

Figure 3 Loading-unloading dependences on organosilicon plasma polymer film deposited at HMDSO to oxygen flow rate ratio of 0.18 and bias voltage of $-110 \mathrm{~V}$ on polycarbonate (on the left) and silicon (on the right) substrates. The thickness of the films was of about $2.2 \mu \mathrm{m}$.
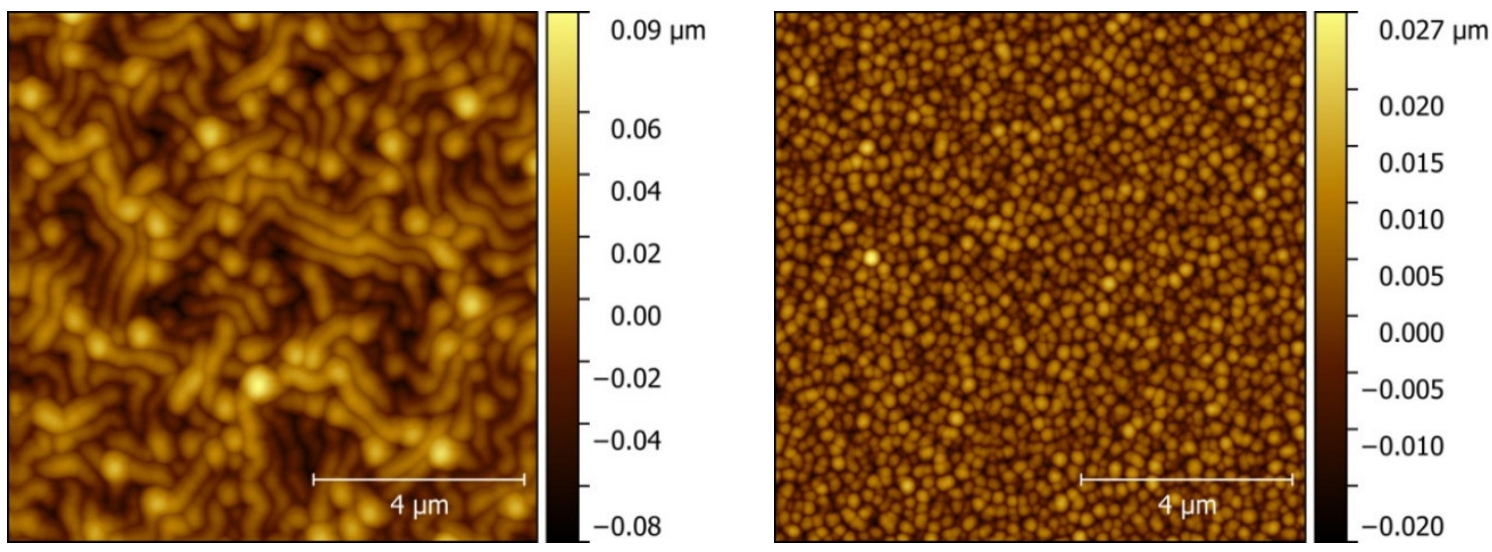

Figure 4 AFM images of the surface structure of films prepared at the same flow rate ratio $q=0.29$ but at different applied power. The surface on the left was prepared at applied power of $P=25 \mathrm{~W}$ and on the right $P$ was $50 \mathrm{~W}$. The deposition time was the same (t=7 min). The thickness of the film on the left side was $920 \mathrm{~nm}$ and the thickness of the film on the right side was $760 \mathrm{~nm}$.
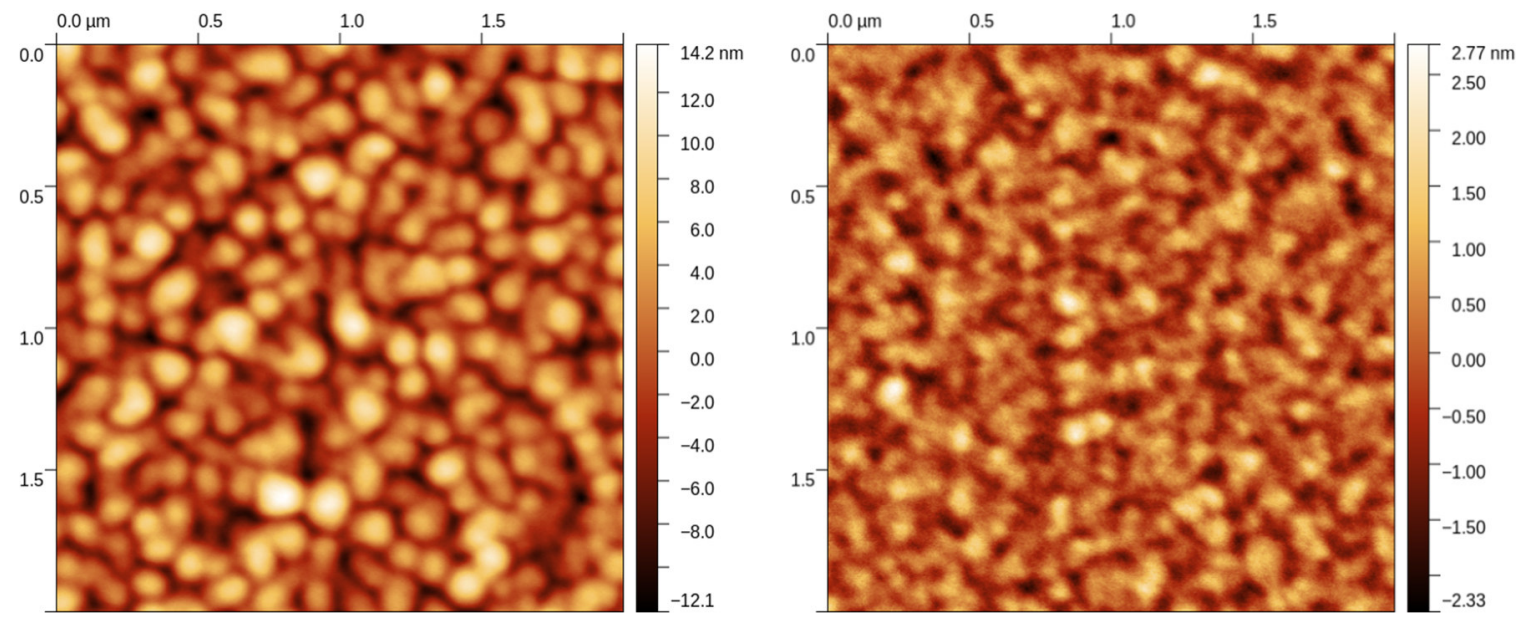

Figure 5 AFM images of the surfaces prepared at flow rate ratio of 0.5 at higher values of applied powers $P$ : On the left $P$ was $75 \mathrm{~W}\left(U_{b}=-100 \mathrm{~V}\right)$ and on the right it was $100 \mathrm{~W}\left(U_{b}=-100 \mathrm{~V}\right)$. 
In Figure 4 the effect applied power on the surface structure is illustrated. The applied power influenced the surface structure, roughness as well as the deposition rate. In case of very low HMDSO fragmentation long intertwined polymer strings were formed on the surface with short side chains. Increase in applied power led to creation of round particles embedded in the growing amorphous matrix.

In Figure 5 two surfaces prepared at higher monomer fragmentation due to higher applied powers are compared. As it can be seen in the figure, with increasing the applied power the size of the particles incorporating into the amorphous matrix has decreasing tendency. This may be explained by the increased kinetic energy of ions impinging the surface of the growing film causing film densification and surface smoothing.

The atomic composition of the films was influenced mainly by the flow rate ratio $q$. According to XPS results, with increased amount of HMDSO in the gas mixture the carbon content in the films increased. The silicon to carbon $(\mathrm{Si} / \mathrm{C})$ ratio decreased from 0.83 to 0.65 and the oxygen to carbon ratio decreased from approximately 1 to 0.65 in case of the flow rate ratio $(q)$ increase from 0.28 to 0.5 . The $\mathrm{C}-\mathrm{C} / \mathrm{C}-\mathrm{H}$ bounds of carbon predominated on the studied surfaces. The $\mathrm{C}-\mathrm{O}$ bonds were the second most abundant carbon bonds. The ratio of $\mathrm{C}-\mathrm{O}$ to $\mathrm{C}-\mathrm{C}$ and $\mathrm{C}-\mathrm{H}$ increased from 0.17 to 0.23 for increase of flow rate ratio $(q)$ from 0.28 to 0.5 . Silicon, which occurs on deposited organosilicon surfaces, was mostly bounded in inorganic $\mathrm{Si}(-\mathrm{O}-)_{4}$ and organic $\mathrm{Si}(-\mathrm{O}-)_{3}(-\mathrm{C}-)$ fragments. In addition, there were observable also $\mathrm{Si}(-\mathrm{O}-)_{2}(-\mathrm{C}-)_{2}$ bonding structures corresponding to siloxane units. All films were transparent and their absorption coefficient was negligible in the visible region.

\section{CONCLUSION}

Transparent organosilicon plasma polymer films were prepared from hexamethyldisiloxan and oxygen mixtures under dusty plasma conditions at relatively high pressures around $40 \mathrm{~Pa}$. The deposited films exhibited properties for wide range of possible applications, e.g. good adherence to substrates, good transparency to visible radiation, high resistance against aging at ambient environment, high elasticity and excellent fracture toughness. In the presented work it was shown, that it is possible to vary the surface structure and properties of the films in a very wide range simply by the variation of the main deposition parameters such the applied power, HMDSO to oxygen flow rate ratio and the DC self bias voltage. It was possible to change the surface free energy from hydrophilic to hydrophobic behaviour.

\section{ACKNOWLEDGEMENTS}

This research has been supported by the Czech Science Foundation under project 19-15240S, by Ministry of Education, Youth and Sports of the Czech Republic under project NPU (LO1411) and by the project Brno Ph.D. Talent. .

\section{REFERENCES}

[1] FAVIA, Pietro, D'AGOSTINO, Riccardo, FRACASSI, Francesco, Plasma and surface diagnostics in PECVD from silicon containing organic monomers. Pure \& Appl. Chem. 1994. vol. 66, no. 6, pp. 1373-1380.

[2] LAMENDOLA, Ritalba D'AGOSTINO, Riccardo, FRACASSI, Francesco, Thin Film Deposition from Hexamethyldisiloxane Fed Glow Discharges. Plasmas and Polymers. 1997, vol. 2, pp. 147-164.

[3] MAGNI, D., DESChENAUX, Ch, HOLlENSTEIN, Ch., CREATORE, A., FAYET, P., Oxygen diluted hexamethyldisiloxane plasma investigated by means of in situ infrared absorption spectroscopy and mass spectrometry. Phys D: Appl Phys. 2001, vol. 34 pp. 87-94.

[4] DREANIK, A., CLERGEREAUX, R., Dusty plasma deposition of nanocomposite thin films. Materiali in Technologije, 2012, 46-1, pp. 13-18. 
[5] LI, D., VRTIS, R., SHAHRAVAN, A., MATSOUKAS T., Plasma-enhanced chemical vapor deposition of organic particle thin films. Journal of Nanoparticle Research. 2011, vol. 13, pp. 985-996.

[6] LEE, S., KANG, Y., JUNG, S., KIM, J., KIM, D., Plasma-Deposited SiOxCyHz Barrier Coatings for Organic Device Encapsulation. Japanese Journal of Applied Physics, 2013, pp. 52-7.

[7] LI, YS., TSAI, CH., KAO, SH., WU, IW., CHEN, JZ., WU, CI., LIN, CF., CHENG, IC., Single-layer organicinorganic-hybrid thin-film encapsulation for organic solar cells. Journal of Physics D-Applied Physics, 2013, pp. 46-43.

[8] BOIES, A. M., Roberts, J. T., GIRSHICK, S. L., Zhang, B., NAKAMURA, T. and MOCHIZUKI, A., SiO 2 coating of silver nanoparticles by photoinduced chemical vapor deposition. Nanotechnology, 2009, pp. 20-29.

[9] KERSTEN, H., WIESE, R., THIEME, G., Examples for application and diagnostics in plasma-powder interaction. New Journal of Physics, 2003, pp. 5-93.

[10] BENITEZ, F., MARTINEZ, E., ESTEVE, J., Improvement of hardness in plasma polymerized hexamethyldisiloxane coatings by silica-like surface modification. Thin Solid Films, 2000, vol. 377, pp. 109-114.

[11] CHARIFOU, R., ESPUCHE, E., GOUANVÉ, F., DUBOST, L., MONACO B., SiOx and SiOxCzHw mono- and multi-layer deposits for improved polymer oxygen and water vapor barrier properties. Journal of Membrane Science, vol. 500, pp. 245-254.

[12] NOUICER, I., SAHLI, S., KIHEL, M., ZIARI, Z., BELLEL, A., Superhydrophobic surface produced on polyimide and silicon by plasma enhanced chemical vapour deposition from hexamethyldisiloxane precursor. International Journal of Nanotechnology, 2014, vol. 12-8,9, pp. 597-607.

[13] GOOD R. J., VAN OSS, C.J. in:Modern Aspects of Wettability, Plenum Press, New York (1992) pp.1-27.

[14] BURSIKOVA, Vilma, HOMOLA, Vojtěch, PERINA, Vratislav., Study of mechanical properties of nanostructured polymer coatings prepared using plasma enhanced chemical vapor deposition, in: NANOCON 2015: 7th International conference on nanomaterials - Research \& Applications, 2015, pp. 105-110. 